\title{
Características agronômicas e de desempenho produtivo de cultivares de milho-verde em sistema orgânico e convencional
}

\section{Agronomic features and yield performance of green corn cultivars in the conventional and organic system}

\author{
Neli Cristina Belmiro dos Santos ${ }^{1 *}$; Silvia Antoniali do Carmo ${ }^{2}$; \\ Gustavo Pavan Mateus ${ }^{1}$; Lauro Kenji Komuro ${ }^{3}$; Leandro Barradas Pereira ${ }^{3}$; \\ Lilian Christian Domingues de Souza ${ }^{3}$
}

\begin{abstract}
Resumo
O milho destinado à produção de espigas verdes apresenta valor de comercialização maior que o milho grão e a demanda ocorre durante todo o ano. Devido à baixa disponibilidade de cultivares específicas e a importância das informações a respeito do cultivo do milho-verde, esse trabalho teve por objetivo avaliar características agronômicas e de desempenho produtivo de cultivares de milho para ser colhido verde nos sistemas de produção orgânico e convencional. Os experimentos foram desenvolvidos no Pólo Regional do Extremo Oeste pertencente à Agência Paulista de Tecnologia dos Agronegócios, em Andradina-SP, durante dois anos agrícolas. O delineamento experimental foi em blocos casualizados, em esquema fatorial 7X2, com quatro repetições. Os tratamentos foram constituídos pela combinação de sete cultivares de milho: AG1051, AG4051, XB7116, 20A55, BM3061, 2B587 (híbridos), Cativerde 02 (variedade) e dois sistemas de cultivo (orgânico e convencional). No sistema orgânico as cultivares foram mais tardias, com menor desenvolvimento e produtividade. Destacaram-se as cultivares 2B587 e BM 3061 com número total de espigas por hectare superior em 14 e 9\%, respectivamente. A cultivar 2B587 foi a mais precoce, com plantas mais baixas e BM3061 apresentou espigas com maior diâmetro e comprimento. As cultivares AG4051 e Cativerde 02 apresentaram plantas mais altas e menos produtivas tanto no sistema convencional quanto no sistema orgânico. As cultivares BM3061, 2B587, XB7116 e AG1051 podem ser recomendadas para os dois sistemas, por serem as mais produtivas em ordem decrescente.
\end{abstract}

Palavras-chave: Zea mays L., híbrido, genótipo, ambiente

\begin{abstract}
The corn used in the production of green ears presents a higher commercialization value compared to corn grain and its demand occurs throughout the year. Due to a small specific cultivation availability and the lack of important information regarding this kind of cultivation, this work has had the objective to evaluate the agronomic characteristics and the production performance in the cultivation of corn to be harvest green in both organic and conventional systems. The experiments have been conducted in "Agência Paulista de Tecnologia dos Agronegócios- Polo Regional do Extremo Oeste", in AndradinaSP, for two agricultural years. The experimental design adopted was in occasionals blocks with 4
\end{abstract}

\footnotetext{
${ }^{1}$ Pesquisadores Científicos, Drs., Agência Paulista de Tecnologia dos Agronegócios, Extremo Oeste, Andradina, SP. E-mail: neli@ apta.sp.gov.br; gpmateus@apta.sp.gov.br

2 Pesquisadora Científica, Dra , Agência Paulista de Tecnologia dos Agronegócios, UPD de Araçatuba, Araçatuba, SP. E-mail: santoniali@apta.sp.gov.br

3 Profs. Drs., Escola Técnica Estadual “Sebastiana Augusta de Moraes”,Andradina, SP. E-mail: komurolk@ig.com.br; 1bpereira25@ hotmail.com; lilianagronomia90@hotmail.com

* Autor para correspondência
} 
repetitions. The treatments have been constituted by the combination of seven cultivate corns: AG1051, AG4051, XB7116, 20A55, BM3061, 2B587 (hybrids) e Cativerde 02 (variety) and 2 systems of organic and conventional cultivation. The organic system presented smaller development and productivity in a delayed period of time. The cultivate 2B587 must be highlighted due to its precocity and smallest height, and BM3061 for presenting corn ears with the longest length and diameter. The cultivates 2B587 and BM 3061 showed a value 14 and 9\%, respectively, higher of total number of ears per hectare. The cultivates AG4051 and Cativerde 02 showed taller and less productive in both systems. The cultivates BM3061, 2B587, XB7116 and AG1051 can be recommended in both systems by being most productive in decreasing order.

Key words: Zea mays L., hybrids, adaptability

\section{Introdução}

O cultivo do milho para colheita de espigas verdes é uma atividade alternativa para pequenos produtores devido ao maior valor de comercialização quando comparado ao milho para produção de grãos. Com alto valor nutritivo, o milho-verde pode ser utilizado para consumo in natura, de espigas cozidas ou processadas, apresentando consumo constante durante o ano. Responsável pelo maior volume distribuído por intermédio da Ceagesp, São Paulo, comercializou 59.627 toneladas de espigas em 2013 (AGRIANUAL, 2015). Para Oliveira et al. (2003) na cultura do milho-verde deve-se observar a porcentagem e o peso de espigas comerciais, maior comprimento e diâmetro médio de espigas, pois a comercialização é feita com base nessas características. Paiva Junior et al. (2001) consideram espigas comerciais, aquelas que, após o despalhamento, apresentam comprimento maior que $15 \mathrm{~cm}$ e diâmetro superior a $3 \mathrm{~cm}$, sem a presença de pragas e doenças.

Como em qualquer cultivo, a escolha das cultivares deve considerar a resistência ou tolerância aos estresses mais prováveis da região (hídrico, nutricional, térmico, radiante, pragas e doenças). As exigências do mercado e a época de semeadura também têm um peso forte na escolha da cultivar (UPNMOOR, 2003).

Para atender o padrão de espigas verdes as cultivares devem apresentar possibilidade de semeadura durante $\mathrm{o}$ ano todo, produtividade acima de $12 \mathrm{tha}^{-1}$, tolerância às principais pragas e doenças, ciclo de 90 a 110 dias, plantas com resistência ao acamamento e quebramento e porte médio para facilitar a colheita. As espigas devem permanecer no ponto de colheita por um longo período, apresentar uniformidade de maturação, forma cilíndrica, bom empalhamento, grãos com equilíbrio entre os teores de açúcar e amido, pedúnculo firme, grãos do tipo dentado e de coloração amarelo clara (BOTTINI; TSUNECHIRO; COSTA, 1995; PEREIRA FILHO et al., 2003). Para Duarte et al. (2004) embora as empresas produtoras de sementes tenham desenvolvido cultivares que atendam às exigências do mercado consumidor de milho-verde, quanto ao tipo de grão, tamanho, formato e empalhamento das espigas e longevidade de colheita, ainda é comum a utilização para essa finalidade de híbridos destinados à produção de grãos e de silagem.

Devido a maior demanda por alimentos orgânicos, o produtor que oferecer espigas de qualidade produzidas organicamente poderá receber $30 \%$ a mais no valor de venda em comparação às produzidas convencionalmente (SANTOS et al., 2005). No entanto, Araújo et al. (2000) citam, que embora o cultivo do milho seja bastante difundido nas principais regiões brasileiras, informações sobre o comportamento de cultivares e características de espigas de milho-verde sob cultivo orgânico são escassas. Os autores verificaram que as variedades IAC Pariquera, IAC Mococa, BRS 4157 e BR 4158 poderiam ser indicadas para este sistema por apresentarem menor incidência de Heliothis Zea, melhor padrão e rendimento de espigas. Pinho et al. (2008) avaliaram a influência do sistema de cultivo 
(orgânico e convencional) em quatro cultivares de milho-verde e, verificaram que o sistema orgânico produziu grãos com maiores valores de $\mathrm{pH}$ e menor acidez titulável, sugerindo maior susceptibilidade a micro-organismos deterioradores e patogênicos que podem potencializar a perecibilidade. A cultivar AG1051 destacou-se por apresentar massa superior de espigas no sistema convencional quando comparado ao orgânico. As demais cultivares não apresentaram diferenças nos dois sistemas, o que permite afirmar que pode-se obter milhoverde orgânico com qualidade de espigas para comercialização.

Assim, nota-se a possibilidade e importância da identificação de cultivares para produção de milho-verde que possam ser introduzidos nos sistemas agrícolas familiares. Este trabalho tem por objetivo avaliar o comportamento de cultivares de milho, quanto as características agronômicas e de desempenho produtivo, para ser colhido verde em sistemas de cultivo orgânico e convencional.

\section{Material e Métodos}

A pesquisa foi desenvolvida na área experimental da APTA/Polo Regional de Desenvolvimento Tecnológico dos Agronegócios do Extremo Oeste, sediado no município de Andradina-SP, localizado na região noroeste do Estado de São Paulo a $379 \mathrm{~m}$ de altitude, 20'55'S e 51'23'W, em duas safras agrícolas.

O clima, segundo a classificação Köpen, é tropical quente e úmido, com inverno seco. O solo do local é classificado como Latossolo Vermelho distrófrico, textura arenosa (EMBRAPA, 2006). As médias das temperaturas máximas foram de 31 e $29{ }^{\circ} \mathrm{C}$ para os anos de 2010 e 2011, respectivamente, e a média das temperaturas mínimas observadas durante o período de execução dos experimentos nos dois anos agrícolas foi de $14^{\circ} \mathrm{C}$.

Em fevereiro de 2010 amostrou-se o solo, na profundidade de $0-0,20 \mathrm{~m}$, para realização de análise química e cálculo de necessidade de calagem e adubação. Os resultados revelaram: $\mathrm{P}=18,50 \mathrm{mg}$ $\mathrm{dm}^{-3} ; \mathrm{pH}\left(\mathrm{CaCl}_{2}\right)=5,3 ; \mathrm{M} . \mathrm{O} .=20,50 \mathrm{~g} \mathrm{dm}^{-3} ; \mathrm{K}^{+}=$ $3,35 \mathrm{mmol}_{\mathrm{c}} \mathrm{dm}^{-3} ; \mathrm{Ca}^{+2}=23,0 \mathrm{mmol}_{\mathrm{c}} \mathrm{dm}^{-3} ; \mathrm{Mg}^{+2}=10$ $\mathrm{mmol}_{\mathrm{c}} \mathrm{dm}^{-3} ; \mathrm{H}+\mathrm{Al}=17 \mathrm{mmol}_{\mathrm{c}} \mathrm{dm}^{-3} \mathrm{e} \mathrm{V}=69 \%$.

$\mathrm{O}$ delineamento experimental utilizado foi de blocos casualizados, com 4 repetições, em esquema fatorial $7 \times 2$. Os tratamentos foram constituídos pela combinação de sete cultivares de milho: AG1051, AG4051, XB7116, 20A55, BM3061, DOW 2B587 (híbridos) e Cativerde 2 (variedade) e dois sistemas de cultivo (convencional e orgânico). As parcelas foram constituídas por cinco linhas de milho espaçadas de $1,0 \mathrm{~m}$ entre si com 5,0 m de comprimento. Dentro da parcela foram consideradas como área útil as três linhas centrais desprezando-se $0,5 \mathrm{~m}$ das extremidades.

A área apresentava capim braquiária (Urochloa decumbens) em pousio, há dois anos, sendo roçada por duas vezes e submetida a uma aração e duas gradagens. Os sistemas de cultivo foram separados por área de transição composta de uma parcela, onde foram executados os tratos culturais de cultivo orgânico e em atendimento à Instrução Normativa $n^{\circ} 64$ de 18 de Setembro de 2008 (BRASIL, 2008).

$\mathrm{O}$ milho foi semeado manualmente em 12/04/2010 e em 12/04/2011, utilizando-se a população de 40 mil plantas $h^{-1}$. A adubação foi realizada considerando a análise de solo e as recomendações de Raij e Cantarella (1996). Nos tratamentos de cultivo convencional foi realizada a adubação com $250 \mathrm{~kg} \mathrm{ha}{ }^{-1}$ da formulação 8-28-16. A adubação de cobertura foi realizada utilizandose $50 \mathrm{~kg} \mathrm{ha}^{-1}$ de nitrogênio na forma de ureia aos 30 dias após a emergência das plantas (DAE), correspondendo ao estádio fenológico V6. Durante o desenvolvimento das plantas, foram executados os tratos culturais e procedimentos fitossanitários normalmente recomendados para a cultura na região. No sistema orgânico a adubação foi realizada com o composto OrganoSuper ${ }^{\circledR}$ na forma granulada na dose de $1750 \mathrm{~kg} \mathrm{ha}^{-1}$. O composto orgânico apresenta aproximadamente $50 \%$ de 
matéria orgânica, 2 a 4\% de P, 3 a 5\% de N, 0,7 a $1,5 \%$ de $\mathrm{K}$ e uma relação $\mathrm{C} / \mathrm{N}$ de 10:1. A adubação de cobertura foi realizada no estádio fenológico V3, ou seja, 15 DAE das plantas com $50 \mathrm{~kg} \mathrm{ha}^{-1} \mathrm{de} \mathrm{N}$ na forma de composto orgânico. O controle de pragas foi efetuado com quatro aplicações de óleo de Nim a $1 \%$. Por ocasiões das pulverizações foram efetuadas adubações foliares alternadamente com fertilizantes organominerais a base de ácidos húmicos fúlvicos (3\%) e proteínas hidrolisadas de pescados marinhos enriquecidos com manganês, zinco e molibdênio $(3 \%)$.

O controle de plantas daninhas em ambos os cultivos foi efetuado por meio de capina manual aos 20 e 35 DAE. No fornecimento de água para a cultura utilizou-se a irrigação por aspersão conforme as necessidades do milho, uma vez que a precipitação pluvial durante o período experimental foi de apenas 31,9 mm em 2010 e 106 mm em 2011.

Foram avaliadas as seguintes características agronômicas:

a) Número de dias para o florescimento: considerou-se o florescimento masculino quando $50 \%$ das plantas das parcelas estavam com as anteras abertas, sendo que o florescimento feminino quando $50 \%$ das plantas apresentavam os estilosestigmas visíveis.

b) Ciclo: foi anotado o número de dias transcorridos entre a emergência das plântulas até a colheita das espigas no estádio R3, grão leitoso.

c) Acúmulo térmico: calculado pelo somatório das unidades térmicas (UT) ocorridas da data da emergência até o florescimento masculino.

d) Massa seca da parte aérea das plantas aos 30, 45, 60 e 90 DAE: a parte aérea de cinco plantas foi cortada no colo da planta e levadas à estufa de ventilação forçada a $60-70{ }^{\circ} \mathrm{C}$ até massa constante.

e) Altura da planta e da espiga: medida em dez plantas seguidas em linha na área útil da parcela aos 90 DAE. f) Massa das espigas com palha e despalhadas: determinou-se a massa das espigas da área útil das parcelas com palha e sem a palha, transformando os dados em $\mathrm{kg} \mathrm{ha}^{-1}$.

g) Número total de espigas: foi determinado através da contagem de todas as espigas da área útil da parcela e posteriormente efetuado o cálculo por ha 1 .

h) Número de espigas comercializáveis: foram consideradas as espigas com padrões exigidos pelo consumidor, conforme Paiva Junior et al. (2001).

i) Massa verde de plantas: após a colheita das espigas, a parte aérea das mesmas plantas foi cortada a $10 \mathrm{~cm}$ do nível do solo e pesada, sendo os dados transformados em $\mathrm{kg} \mathrm{ha}^{-1}$.

j) Massa das brácteas: Calculada através da subtração da massa das espigas com palha e sem palha e espigas fora do padrão comercial, sendo os dados transformados em $\mathrm{kg} \mathrm{ha}{ }^{-1}$.

k) Diâmetro médio de espiga despalhada: com auxílio de paquímetro digital mediu-se o diâmetro na parte mediana das espigas comerciais $(\mathrm{cm})$ por parcela na ocasião da colheita.

1) Comprimento médio de espiga despalhada: determinou-se o comprimento das espigas comerciais $(\mathrm{cm})$ por parcela na ocasião da colheita.

Os dados obtidos foram submetidos à análise da variância e as médias comparadas pelo teste de Tukey $(\mathrm{P}<0,05)$ para cada ano separadamente.

\section{Resultados e Discussão}

As plantas em sistema convencional apresentaram inflorescências 3 a 12 dias antes que as submetidas ao sistema orgânico, além de completarem o ciclo mais precocemente (Tabela 1). As cultivares pendoaram por volta dos 54 aos 57 DAE no sistema convencional e 60 a 70 DAE no orgânico. Quanto ao florescimento feminino, este ocorreu aos 57 DAE nas cultivares mais precoces 
e aos 60 DAE nas cultivares de ciclo mais longo. As cultivares de milho são classificadas quanto à duração do seu ciclo em função do número de unidades de calor que requerem para florescer. De acordo com Cruz e Pereira Filho (2008), as cultivares normais apresentam exigência térmica superior a 890 graus-dias (G.D.), as precoces, de 830 a 890 G.D., e as superprecoces, menor do que 830 G.D. O sistema de cultivo orgânico alterou a classificação das cultivares AG 1051, AG 4051, Cativerde 02 que eram consideradas normais e tornaram-se superprecoces. As cultivares XB 7116 e 20A55 passaram de precoce no sistema convencional para superprecoces no sistema orgânico. Não apresentaram alteração com o sistema de cultivo, a cultivar 2B587 superprecoce, completando o ciclo em 85 DAE no sistema convencional e 92 DAE no orgânico e, a cultivar BM3061 que apresentou ciclo normal. Essas diferenças de ciclo devem estar diretamente relacionadas a capacidade de responder aos estímulos do ambiente. Provavelmente, diferenças na profundidade alcançada pelo sistema radicular, habilidade em competir com plantas daninhas, eficiência na absorção e uso de nutrientes tenham influenciado o desenvolvimento das cultivares, o que pode proporcionar vantagens na adaptação às condições ambientais. Para), a preferência por cultivares de milho precoce e de porte reduzido, facilita a Bordallo et al. (2005incorporação de restos culturais, nos casos em que o produtor tem interesse em utilizar intensivamente a área, realizando diversos cultivos consecutivos, de forma a obter várias colheitas por ano no mesmo local.

Tabela 1. Médias do número de dias para florescimento masculino, feminino, ciclo e acúmulo térmico de cultivares de milho-verde sob cultivo convencional e orgânico em 2010 e 2011, Andradina-SP.

\begin{tabular}{lcccl}
\hline \multicolumn{1}{c}{ Tratamentos } & $\begin{array}{c}\text { Dias para } \\
\text { florescimento } \\
\text { masculino }\end{array}$ & $\begin{array}{c}\text { Dias para } \\
\text { florescimento } \\
\text { feminino }\end{array}$ & $\begin{array}{c}\text { Ciclo } \\
\text { (DAE)* }\end{array}$ & $\begin{array}{c}\text { Acúmulo Térmico/ } \\
\text { Classificação }\end{array}$ \\
\hline 1 - AG1051 convencional & 54 & 57 & 92 & $746 /$ Superprecoce \\
2 - AG1051 orgânico & 66 & 69 & 95 & $915 /$ Normal \\
3 - AG4051 convencional & 57 & 60 & 93 & $789 /$ Superprecoce \\
4 - AG4051 orgânico & 66 & 69 & 95 & $915 /$ Normal \\
5 - XB7116 convencional & 54 & 57 & 92 & $746 /$ Superprecoce \\
6 - XB7116 orgânico & 66 & 69 & 95 & $915 /$ Precoce \\
7 - Cativerde 2 convencional & 57 & 60 & 92 & $789 /$ Superprecoce \\
8 - Cativerde 2 orgânico & 67 & 70 & 96 & $929 /$ Normal \\
9 - 20A55 convencional & 57 & 60 & 93 & $789 /$ Superprecoce \\
10 - 20A55 orgânico & 61 & 64 & 93 & $843 /$ Precoce \\
11 - BM3061 convencional & 67 & 70 & 93 & $915 /$ Normal \\
12 - BM3061 orgânico & 70 & 73 & 96 & 971/Normal \\
13 - 2B587 convencional & 54 & 57 & 85 & $746 /$ Superprecoce \\
14 - 2B587 orgânico & 60 & 63 & 92 & 789/Superprecoce \\
\hline
\end{tabular}

*DAE- Dias após a emergência das plantas.

Fonte: Elaboração dos autores.

Em 2010, houve interação significativa entre cultivar e sistema de cultivo para massa seca de plantas aos 30 e 90 DAE (Tabela 2). Aos 30 DAE as cultivares sob cultivo convencional não diferiram entre si, porém no sistema orgânico destacou-se a cultivar XB7116, com menor massa seca de plantas. 
Apenas as cultivares AG1051 e XB7116 apresentaram menor massa seca no sistema orgânico quando comparado com o sistema convencional. Aos 45 e $60 \mathrm{DAE}$ as cultivares apresentaram comportamento semelhante e acumularam menor massa seca no sistema orgânico quando comparado ao sistema convencional. No final do ciclo (90 DAE) destacouse a cultivar 2B587 por apresentar a menor massa entre as cultivares nos dois sistemas, com cerca de $120 \mathrm{~g} \mathrm{planta}^{-1}$, devido a sua precocidade em relação às demais. Houve diferença estatística no acúmulo de massa entre os sistemas apenas para AG4051 e XB7116, que apresentaram menor valor no sistema orgânico. As demais cultivares não apresentaram diferença para essa variável. Desta forma, podese inferir que, embora com crescimento mais lento no início, as plantas produzidas organicamente conseguiram recuperar-se e igualar-se às do sistema convencional no final do ciclo. Em 2011, houve efeito isolado de cultivar e sistema de cultivo sobre a massa seca de plantas (Tabela 3). Até os $45 \mathrm{DAE}$ as cultivares Cativerde 2, 20A55, AG1051 e AG4051 apresentaram menor massa seca quando comparadas as demais. A partir dos 60 DAE não houve diferença no acúmulo de massa seca entre as cultivares. Em todo o ciclo as cultivares sob cultivo orgânico apresentaram menor massa quando comparadas às do sistema convencional.

Tabela 2. Desdobramento das interações significativas entre sistema de cultivo e cultivar para massa seca da parte aérea aos 30 e 90 dias após a emergência de milho-verde e médias de massa seca da parte aérea aos 45 e 60 dias após a emergência em 2010, Andradina-SP.

\begin{tabular}{|c|c|c|c|c|c|c|}
\hline \multirow{3}{*}{$\begin{array}{l}\text { Tratamentos } \\
\text { Cultivar }\end{array}$} & \multicolumn{6}{|c|}{ Massa seca $\left(\right.$ g planta $\left.^{-1}\right)$} \\
\hline & \multicolumn{2}{|c|}{30 DAE } & \multirow[t]{2}{*}{ 45 DAE } & \multirow[t]{2}{*}{ 60 DAE } & \multicolumn{2}{|c|}{90 DAE } \\
\hline & Convencional & Orgânico & & & Convencional & Orgânico \\
\hline AG1051 & $29,33 \mathrm{Aa}$ & $18,00 \mathrm{Bab}$ & $47,94 a$ & $99,83 a$ & $169,07 \mathrm{Aab}$ & $165,47 \mathrm{Aab}$ \\
\hline AG4051 & $21,00 \mathrm{Aa}$ & $25,75 \mathrm{Aa}$ & $43,12 \mathrm{a}$ & $82,66 a$ & $179,20 \mathrm{Aab}$ & $126,69 \mathrm{Bbc}$ \\
\hline XB7116 & $27,25 \mathrm{Aa}$ & $14,50 \mathrm{Bb}$ & $40,92 \mathrm{a}$ & $93,42 \mathrm{a}$ & $182,29 \mathrm{Aab}$ & $140,39 \mathrm{Babc}$ \\
\hline Cativerde 2 & $23,75 \mathrm{Aa}$ & $20,67 \mathrm{Aab}$ & $51,40 \mathrm{a}$ & $104,33 a$ & $176,69 \mathrm{Aab}$ & $155,70 \mathrm{Aabc}$ \\
\hline $20 \mathrm{~A} 55$ & $19,50 \mathrm{Aa}$ & $16,50 \mathrm{Aab}$ & $37,78 \mathrm{a}$ & $94,56 \mathrm{a}$ & $145,22 \mathrm{Abc}$ & 149,30Aabc \\
\hline BM3061 & $22,75 \mathrm{Aa}$ & $21,88 \mathrm{Aab}$ & $52,24 \mathrm{a}$ & $102,52 \mathrm{a}$ & $194,12 \mathrm{Aa}$ & $175,18 \mathrm{Aa}$ \\
\hline 2B587 & $25,65 \mathrm{Aa}$ & $20,65 \mathrm{Aab}$ & $48,53 \mathrm{a}$ & $90,80 \mathrm{a}$ & $107,15 \mathrm{Ac}$ & $120,11 \mathrm{Ac}$ \\
\hline DMS C (S) & \multicolumn{2}{|c|}{6,97} & & & \multicolumn{2}{|c|}{43,11} \\
\hline DMS S (C) & \multicolumn{2}{|c|}{10,72} & & & \multicolumn{2}{|c|}{28,06} \\
\hline Convencional & & & $59,41 \mathrm{a}$ & $117,44 a$ & & \\
\hline Orgânico & & & $32,56 \mathrm{~b}$ & $73,45 b$ & & \\
\hline Média & \multicolumn{2}{|c|}{21,94} & 45,99 & 95,44 & \multicolumn{2}{|c|}{156,19} \\
\hline \multicolumn{7}{|l|}{ Teste F } \\
\hline Cultivar (C) & \multicolumn{2}{|c|}{$1,31^{\mathrm{ns}}$} & $1,52^{\mathrm{ns}}$ & $1,54^{\mathrm{ns}}$ & \multicolumn{2}{|c|}{$10,26^{* *}$} \\
\hline Sistema (S) & \multicolumn{2}{|c|}{$11,76^{* *}$} & $63,75^{* *}$ & $92,60^{* *}$ & \multicolumn{2}{|c|}{$10,84^{* *}$} \\
\hline $\mathrm{CXS}$ & \multicolumn{2}{|c|}{$3,05^{*}$} & $1,03^{\mathrm{ns}}$ & $0,31^{\mathrm{ns}}$ & \multicolumn{2}{|c|}{$2,96^{*}$} \\
\hline C.V. \% & \multicolumn{2}{|c|}{22,23} & 27,35 & 17,92 & \multicolumn{2}{|c|}{12,56} \\
\hline
\end{tabular}

**, * e ns - significativo em nível de $1 \%, 5 \%$ de probabilidade e não significativo, respectivamente, pelo teste $\mathrm{F}$.

Médias seguidas pela mesma letra, minúscula na coluna e maiúscula na linha, não diferem entre si, pelo teste de Tukey, a 5\% de significância.

DAE - dias após a emergência das plantas.

Fonte: Elaboração dos autores.

Em sistema de cultivo orgânico as plantas de cultivo (Tabela 4). Houve efeito da interação apresentaram menores estaturas nos dois anos entre cultivares e sistemas para altura das 
plantas e da primeira espiga no primeiro ano. No sistema convencional as plantas mais altas foram observadas em AG4051 com 2,61m seguidas de Cativerde 2, AG1051 e BM3061. As menores alturas de plantas e de inserção das espigas foram observadas nas cultivares 2B587 e 20A55. No sistema orgânico, a altura máxima de planta foi de 2,12 m na cultivar BM3061, embora esta não tenha diferido de AG4051 e AG1051. A cultivar 2B587 foi a que apresentou a menor altura de espigas, com 0,70 e 0,91 m do solo, nos sistema orgânico e convencional, respectivamente.

Tabela 3. Médias de massa seca da parte aérea aos 30, 45, 60 e 90 dias após a emergência de milho-verde cultivado em sistema orgânico e convencional em 2011, Andradina-SP.

\begin{tabular}{|c|c|c|c|c|}
\hline \multirow{2}{*}{\begin{tabular}{l}
\multicolumn{1}{c}{ Tratamentos } \\
Cultivar
\end{tabular}} & \multicolumn{4}{|c|}{ Massa seca (g planta-1) } \\
\hline & 30 DAE & 45 DAE & 60 DAE & 90 DAE \\
\hline AG1051 & $16,35 \mathrm{bc}$ & $59,20 \mathrm{ab}$ & $103,37 \mathrm{a}$ & $227,44 a$ \\
\hline AG4051 & $14,80 \mathrm{c}$ & $63,06 a b$ & $105,49 \mathrm{a}$ & $222,63 a$ \\
\hline XB7116 & $21,80 \mathrm{a}$ & $75,91 \mathrm{a}$ & $114,86 \mathrm{a}$ & $223,82 a$ \\
\hline Cativerde 2 & $15,20 \mathrm{bc}$ & $54,58 \mathrm{~b}$ & $104,50 \mathrm{a}$ & $230,02 \mathrm{a}$ \\
\hline $20 \mathrm{~A} 55$ & $15,30 \mathrm{bc}$ & $59,59 \mathrm{ab}$ & $103,02 \mathrm{a}$ & $198,94 \mathrm{a}$ \\
\hline ВM3061 & $21,70 \mathrm{a}$ & $74,57 \mathrm{a}$ & $109,72 \mathrm{a}$ & $284,13 a$ \\
\hline 2B587 & $19,45 \mathrm{ab}$ & $65,30 \mathrm{ab}$ & $99,52 \mathrm{a}$ & $184,83 \mathrm{a}$ \\
\hline \multicolumn{5}{|l|}{ Sistema de cultivo } \\
\hline Convencional & $21,61 \mathrm{a}$ & $79,25 \mathrm{a}$ & $124,93 a$ & $257,45 \mathrm{a}$ \\
\hline Orgânico & $13,98 \mathrm{~b}$ & $49,95 \mathrm{~b}$ & $86,63 \mathrm{~b}$ & $191,63 \mathrm{~b}$ \\
\hline Média & 17,81 & 64,61 & 105,79 & 224,54 \\
\hline \multicolumn{5}{|l|}{ Teste F } \\
\hline Cultivar (C) & $8,73^{* *}$ & $3,18^{*}$ & $0,54^{\mathrm{ns}}$ & $1,76^{\mathrm{ns}}$ \\
\hline Sistema (S) & $91,92^{* *}$ & $74,53^{* *}$ & $54,41^{* *}$ & $13,78^{* *}$ \\
\hline CXS & $1,93^{\mathrm{ns}}$ & $1,42^{\mathrm{ns}}$ & $1,77^{\mathrm{ns}}$ & $0,93^{\mathrm{ns}}$ \\
\hline C.V. $\%$ & 16,73 & 19,66 & 18,36 & 29,55 \\
\hline
\end{tabular}

**,* e ns - significativo em nível de $1 \%, 5 \%$ de probabilidade e não significativo, respectivamente, pelo teste $\mathrm{F}$.

Médias seguidas pela mesma letra não diferem entre si, dentro de cultivar e de sistema de cultivo nas colunas, pelo teste de Tukey, a 5\% de significância.

DAE - dias após a emergência das plantas.

Fonte: Elaboração dos autores.

As diferenças de alturas entre as plantas dos dois sistemas no segundo ano foram menores, porém plantas sob cultivo convencional foram $21 \mathrm{~cm}$ mais altas quando comparadas as do cultivo orgânico. A amplitude de variação de altura foi de 1,92 a 2,61m no sistema convencional e de 1,61 a 2,07 $\mathrm{m}$ no cultivo orgânico. Assim, todas as cultivares apresentaram porte médio, considerado adequado para produção de espigas verdes, pois facilita a colheita, que é manual (BOTTINI; TSUNECHIRO; COSTA, 1995). No entanto, os valores de altura de plantas alcançadas pelas cultivares estudadas estiveram acima dos obtidos por Rocha, Fornasieri Filho e Barbosa (2011), pois as plantas completaram o ciclo mais tardiamente devido as temperaturas mais baixas no local do experimento. Para Parentoni et al. (1990) plantas mais altas e mais tardias, geralmente produzem mais massa e devem ser preferidas quando se pretende utilizar os restos culturais na alimentação de bovinos.

A comercialização de milho verde pode ser realizada na forma de espigas empalhadas em feiras livres, sacolões e quitandas e, espigas despalhadas e embaladas em filme plástico de PVC em 
supermercados. Nestes casos, o maior número de espigas totais e comerciais é desejável. Porém, quando a comercialização ocorre em mercados atacadistas, na forma de espigas empalhadas e ensacadas, a produtividade é medida pelos produtores em massa de espigas com palha (ALBUQUERQUE et al., 2008). Deste modo, o desempenho produtivo das cultivares foi avaliado com base nessas características.

Tabela 4. Desdobramento das interações significativas entre sistema de cultivo e cultivar para altura de plantas e altura da primeira espiga em 2010 e médias de altura de plantas e da primeira espiga aos 90 dias após a emergência de milhoverde em 2011, Andradina-SP.

\begin{tabular}{|c|c|c|c|c|}
\hline \multirow[t]{3}{*}{ Tratamentos } & \multicolumn{2}{|c|}{ Altura de plantas (m) } & \multicolumn{2}{|c|}{ Altura da primeira espiga (m) } \\
\hline & \multicolumn{3}{|c|}{2010} & \multirow[b]{2}{*}{ Orgânico } \\
\hline & Convencional & Orgânico & Convencional & \\
\hline AG1051 & $2,47 \mathrm{Aab}$ & $2,03 \mathrm{Bab}$ & $1,33 \mathrm{Aa}$ & $1,10 \mathrm{Ba}$ \\
\hline AG4051 & 2,61Aa & $2,07 \mathrm{Bab}$ & $1,23 \mathrm{Aa}$ & $0,97 \mathrm{Bab}$ \\
\hline XB7116 & $2,35 \mathrm{Abc}$ & $1,84 \mathrm{Bbc}$ & $1,26 \mathrm{Aa}$ & $0,91 \mathrm{Bbc}$ \\
\hline Cativerde 2 & $2,50 \mathrm{Aab}$ & $1,91 \mathrm{Bbc}$ & $1,33 \mathrm{Aa}$ & $0,96 \mathrm{Babc}$ \\
\hline $20 \mathrm{~A} 55$ & $2,19 \mathrm{Ac}$ & $1,89 \mathrm{Bbc}$ & $0,92 \mathrm{Ab}$ & $0,77 \mathrm{Bcd}$ \\
\hline ВM3061 & $2,46 \mathrm{Aab}$ & $2,12 \mathrm{Ba}$ & $1,27 \mathrm{Aa}$ & $1,07 \mathrm{Bab}$ \\
\hline 2B587 & $2,07 \mathrm{Ad}$ & $1,61 \mathrm{Bd}$ & $0,91 \mathrm{Ab}$ & $0,70 \mathrm{Be}$ \\
\hline DMS C (S) & \multicolumn{2}{|c|}{0,18} & \multicolumn{2}{|c|}{0,14} \\
\hline DMS S (C) & \multicolumn{2}{|c|}{0,12} & \multicolumn{2}{|c|}{0,09} \\
\hline Média & \multicolumn{2}{|c|}{2,15} & \multicolumn{2}{|c|}{1,05} \\
\hline \multicolumn{5}{|l|}{ Teste F } \\
\hline Cultivar (C) & \multicolumn{2}{|c|}{$35,47^{* *}$} & \multicolumn{2}{|c|}{$48,53^{* *}$} \\
\hline Sistema (S) & \multicolumn{2}{|c|}{$428,77^{* *}$} & \multicolumn{2}{|c|}{$211,21^{* *}$} \\
\hline CXS & \multicolumn{2}{|c|}{$3,48^{* *}$} & \multicolumn{2}{|c|}{$3,07^{*}$} \\
\hline \multirow[t]{2}{*}{$\mathrm{CV} \%$} & \multicolumn{2}{|c|}{3,82} & \multicolumn{2}{|c|}{6,25} \\
\hline & \multicolumn{4}{|c|}{2011} \\
\hline AG1051 & \multicolumn{2}{|c|}{$2,26 a b$} & \multicolumn{2}{|c|}{$1,29 \mathrm{ab}$} \\
\hline AG4051 & \multicolumn{2}{|c|}{$2,35 \mathrm{a}$} & \multicolumn{2}{|c|}{$1,20 \mathrm{~b}$} \\
\hline XB7116 & \multicolumn{2}{|c|}{$2,19 b$} & \multicolumn{2}{|c|}{$1,26 \mathrm{ab}$} \\
\hline Cativerde 2 & \multicolumn{2}{|c|}{$2,32 \mathrm{ab}$} & \multicolumn{2}{|c|}{$1,33 \mathrm{a}$} \\
\hline $20 \mathrm{~A} 55$ & & & & \\
\hline BM3061 & & & & \\
\hline 2B587 & & & & \\
\hline Convencional & & & & \\
\hline Orgânico & & & & \\
\hline Média & & & & \\
\hline Teste F & & & & \\
\hline Cultivar (C) & & & & \\
\hline Sistema (S) & & & & \\
\hline CXS & & & & \\
\hline C.V. $\%$ & & & & \\
\hline
\end{tabular}

**, * e ns - significativo em nível de $1 \%, 5 \%$ de probabilidade e não significativo, respectivamente, pelo teste $\mathrm{F}$.

Médias seguidas de letra minúscula na coluna e maiúscula na linha não diferem entre si, pelo teste de Tukey, a $5 \%$ de significância. Fonte: Elaboração dos autores.

As médias do número total e comercial de e despalhadas no primeiro e no segundo ano de espigas, bem como a massa de espigas empalhadas experimentação estão apresentadas na Tabela 5. 
Não houve efeito do sistema de cultivo para o número total de espigas, sendo a diferença de apenas 1562 e 982 espigas ha $^{-1}$, no primeiro e segundo ano, respectivamente. A média de produtividade para ambos os sistemas foi de 45000 espigas ha1. Utilizando híbridos simples e triplos em cultivo convencional, Vieira et al. (2010) obtiveram de 18400 a 36000 espigas ha $^{-1}$, portanto produtividades menores as obtidas no presente estudo. Para número de espigas comerciais houve diferenças no sistema de cultivo apenas no primeiro ano, sendo que o cultivo convencional produziu 5.446 mais espigas comerciais quando comparado ao sistema orgânico. A cultivar 2B587 foi a mais produtiva em número de espigas totais e comerciais, embora não tenha diferido estatisticamente de BM3061 XB7116 e AG1051.

Tabela 5. Médias de número total e comercial de espigas, massa de espigas com palha e despalhadas de milho-verde cultivado em sistema orgânico e convencional em 2010 e 2011, Andradina-SP.

\begin{tabular}{|c|c|c|c|c|}
\hline Tratamentos & $\begin{array}{l}\text { Número total de } \\
\text { espigas }^{\text {ha-1 }}\end{array}$ & 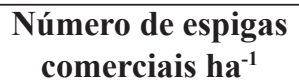 & $\begin{array}{l}\text { Massa de espigas } \\
\text { com palha ha' } \text { hag) }^{-1}(\mathrm{~kg})\end{array}$ & $\begin{array}{c}\text { Massa de espigas } \\
\text { despalhadas ha-1 }(\mathrm{kg})\end{array}$ \\
\hline Cultivar & \multicolumn{4}{|c|}{2010} \\
\hline AG1051 & 49843abc & $42031 \mathrm{ab}$ & $16730 \mathrm{ab}$ & $9855 \mathrm{ab}$ \\
\hline AG4051 & $43125 \mathrm{~cd}$ & $35937 b c$ & $14293 b c$ & $9204 b c$ \\
\hline XB7116 & $52656 a$ & $47031 \mathrm{a}$ & $17202 \mathrm{ab}$ & $9793 \mathrm{ab}$ \\
\hline Cativerde 2 & $39531 d$ & $32500 \mathrm{c}$ & $12464 \mathrm{c}$ & $7321 \mathrm{c}$ \\
\hline $20 \mathrm{~A} 55$ & $43750 \mathrm{bcd}$ & $37343 b c$ & $15839 \mathrm{abc}$ & $10623 \mathrm{ab}$ \\
\hline BM3061 & $51875 \mathrm{ab}$ & $47187 \mathrm{a}$ & 18931a & $10654 \mathrm{ab}$ \\
\hline 2B587 & $54375 \mathrm{a}$ & $50468 \mathrm{a}$ & $17095 \mathrm{ab}$ & $11186 a$ \\
\hline \multicolumn{5}{|l|}{ Sistema de cultivo } \\
\hline Convencional & $48660 \mathrm{a}$ & $44508 \mathrm{a}$ & $17354 a$ & $10398 \mathrm{a}$ \\
\hline Orgânico & $47098 \mathrm{a}$ & $39062 b$ & $14804 \mathrm{~b}$ & $9213 b$ \\
\hline Média & 47879 & 41785 & 16079 & 9805 \\
\hline \multicolumn{5}{|l|}{ Teste F } \\
\hline Cultivar (C) & $8,69^{* *}$ & $9,76^{* *}$ & $7,85^{* *}$ & $8,41^{* *}$ \\
\hline Sistema (S) & $1,15^{\mathrm{ns}}$ & $11,16^{* *}$ & $19,74^{* *}$ & $12,72^{* *}$ \\
\hline CXS & $0,10^{\text {ns }}$ & $0,50^{\mathrm{ns}}$ & $0,46^{\mathrm{ns}}$ & $0,77^{\mathrm{ns}}$ \\
\hline C.V. $\%$ & 11,40 & 14,60 & 13,36 & 12,68 \\
\hline Cultivar & \multicolumn{4}{|c|}{2011} \\
\hline AG1051 & 42187bcd & $36250 \mathrm{bcd}$ & $16242 \mathrm{ab}$ & $7625 b$ \\
\hline AG4051 & $38437 d$ & $32187 d$ & $14406 b \mathrm{c}$ & $7594 b$ \\
\hline XB7116 & $44375 a b c$ & $40312 \mathrm{ab}$ & $16046 a b$ & $8645 \mathrm{ab}$ \\
\hline Cativerde 2 & $40312 \mathrm{bcd}$ & $32500 \mathrm{~cd}$ & $13683 \mathrm{c}$ & $7495 b$ \\
\hline $20 \mathrm{~A} 55$ & $39219 \mathrm{~cd}$ & $33593 \mathrm{~cd}$ & $14732 \mathrm{abc}$ & $8613 a b$ \\
\hline BM3061 & $45469 \mathrm{ab}$ & $38906 a b c$ & $16777 \mathrm{a}$ & $8981 \mathrm{ab}$ \\
\hline 2B587 & $48437 \mathrm{a}$ & $45156 a$ & $16821 \mathrm{a}$ & $10124 a$ \\
\hline \multicolumn{5}{|l|}{ Sistema de cultivo } \\
\hline Convencional & $42142 a$ & $37946 a$ & $16428 \mathrm{a}$ & $8739 a$ \\
\hline Orgânico & $43125 \mathrm{a}$ & $36026 a$ & $14632 b$ & $8141 \mathrm{a}$ \\
\hline Média & 42634 & 36986 & 15530 & 8440 \\
\hline \multicolumn{5}{|l|}{ Teste F } \\
\hline Cultivar (C) & $9,43^{* *}$ & $9,81^{* *}$ & $5,66^{* *}$ & $3,18^{*}$ \\
\hline Sistema (S) & $1,20^{\mathrm{ns}}$ & $2,78^{\mathrm{ns}}$ & $20,60^{* *}$ & $2,18^{\mathrm{ns}}$ \\
\hline CXS & $2,21^{\mathrm{ns}}$ & $1,36^{\mathrm{ns}}$ & $2,16^{\mathrm{ns}}$ & $1,90^{\text {ns }}$ \\
\hline C.V. \% & 7,87 & 11,65 & 9,53 & 17,93 \\
\hline
\end{tabular}

**, * e ns - significativo em nível de $1 \%, 5 \%$ de probabilidade e não significativo, respectivamente, pelo teste $\mathrm{F}$.

Médias seguidas pela mesma letra não diferem entre si, pelo teste de Tukey, a 5\% de significância.

Fonte: Elaboração dos autores. 
Houve efeito de cultivar e sistema de cultivo na massa de espigas despalhadas e empalhadas e nos dois anos. A cultivar BM3061 foi a mais produtiva com média nos dois anos de $17854 \mathrm{~kg} \mathrm{ha}^{-1}$ de espigas empalhadas, no entanto não diferiu de 2B587, XB7116 e AG1051. A produção de espigas empalhadas em sistema orgânico foi menor em $2550 \mathrm{~kg} \mathrm{ha}^{-1}$, ou seja, 14,7\%, quando comparada ao convencional no primeiro ano de cultivo e de apenas $1796 \mathrm{~kg} \mathrm{ha}^{-1}$ no segundo ano, indicando que as diferenças entre os dois sistemas foram menores com o tempo de cultivo. No sistema convencional a média de produtividade foi de $16891 \mathrm{~kg} \mathrm{ha}^{-1}$ espigas empalhadas, inferior à relatada por Albuquerque et al. (2008), devido a menor população de plantas utilizada (40000 plantas ha-1). No sistema orgânico foi de $14718 \mathrm{~kg} \mathrm{ha}^{-1}$, portanto superiores à considerada como ideal por Pereira Filho et al. (2003). As menores produtividades foram observadas em Cativerde 2, AG4051 e 20A55. Produtividades semelhantes, torno de $14860 \mathrm{~kg} \mathrm{ha}^{-1}$, foram encontradas por Freire et al. (2010) utilizando o híbrido AG4051 em cultivo convencional utilizando a dose máxima de nitrogênio em cobertura de $177 \mathrm{~kg} \mathrm{ha}^{-1}$ e 50000 plantas ha-1.

A massa de espigas despalhadas apresentou efeito do sistema de cultivo apenas no primeiro ano e de cultivar nos dois anos de experimentação (Tabela 5). Em 2010 a produtividade obtida no sistema convencional foi $1185 \mathrm{~kg} \mathrm{ha}^{-1}$ a mais quando comparada ao sistema orgânico, no entanto em 2011 a diferença foi de apenas $598 \mathrm{~kg} \mathrm{ha}^{-1}$. O híbrido 2B587 foi o que apresentou maior massa de espigas despalhadas seguido de BM3061, XB7116 e 20A55. A variedade Cativerde 2 e o híbrido AG4051 foram menos produtivos para essas características. No entanto, Rocha, Fornasieri Filho e Barbosa (2011) verificaram superioridade na produção dos híbridos AG4051, AG1051 e BM3061 sobre a variedade Cativerde 2, pois normalmente as variedades apresentam menor potencial devido ao vigor híbrido. Diferenças no comportamento de híbrido e variedade também foram verificados por Santos Arf e Komuro (2010) ao estudar o híbrido XB7116 e a variedade
Cativerde 2 para a produção de espigas verdes, em sistema convencional e irrigação. Os autores relatam que, embora o híbrido produza maior quantidade, espigas maiores e mais uniformes, possui grãos duros e alaranjados comparado com a variedade, que apresenta grão amarelo claro com endosperma mole, mais preferido pelo consumidor. No entanto, Cardoso, Carvalho e Ribeiro (2004) observaram produtividade semelhante entre 21 variedades de polinização aberta e híbridos para produção de espigas verdes em sistemas agrícolas familiares. Selecionaram 9 variedades com produtividade acima de $11000 \mathrm{~kg}$ de espigas despalhadas ha-1. Para Cruz et al. (2008) a utilização de variedades para produção de milho grão é uma alternativa viável nos sistemas orgânicos, devido ao baixo custo e produtividade superior aos híbridos. Ainda, o uso de variedades nesse sistema proporcionaria maior autonomia ao produtor em produzir sua própria semente.

O sistema orgânico produziu menor massa de brácteas e de massa verde quando comparado ao sistema convencional nos dois anos (Tabela 6). As cultivares comportaram-se diferentemente quanto à massa de brácteas e produção de massa verde das plantas após a colheita, resíduos que podem ser aproveitados na propriedade para alimentação animal. Destacaram-se as cultivares BM3061, AG1051 e XB7116, como as mais produtivas em massa de brácteas e BM3061, AG1051 e Cativerde 2 para massa verde de plantas, considerando os dois anos agrícolas.

O diâmetro e o comprimento de espigas são características importantes quando a comercialização ocorre por unidades ou bandejas de poliestireno expandido recobertos com película de PVC. Albuquerque et al. (2008) afirmam que o consumidor prefere espigas de maior diâmetro e comprimento, com grãos de cor creme a amareloclaro. Os autores verificaram a existência de correlação positiva entre a altura de plantas e o comprimento de espigas, de forma que plantas altas produzem espigas maiores e mais pesadas. Neste estudo, verificou-se que apenas a cultivar BM3061 
apresentou plantas altas e com maiores espigas. Em cultivo orgânico as espigas apresentaram menor diâmetro quando comparadas às do cultivo convencional. O efeito do cultivo orgânico sobre o tamanho das espigas pode ser devido a falta de nutrientes prontamente disponíveis nesse sistema, pois Freire et al. (2010) verificaram que o nitrogênio em cobertura proporcionou espigas de maior diâmetro no híbrido AG4051. Verificou-se que a variedade Cativerde 2 foi a que apresentou espigas comerciais mais finas, embora não tenha diferido significativamente de XB7116.

Tabela 6. Médias de massa de brácteas, massa verde de plantas e diâmetro comercial de espigas de milho-verde cultivado em sistema orgânico e convencional em 2010 e 2011, Andradina-SP.

\begin{tabular}{|c|c|c|c|}
\hline Tratamentos & $\begin{array}{l}\text { Massa das brácteas } \\
\left(\mathrm{kg} \mathrm{ha}^{-1}\right)\end{array}$ & $\begin{array}{c}\text { Massa verde } \\
\left(\mathrm{kg} \mathrm{ha}^{-1}\right)\end{array}$ & $\begin{array}{c}\text { Diâmetro de espigas } \\
(\mathrm{mm})\end{array}$ \\
\hline Cultivar & & 2010 & \\
\hline AG1051 & $6874 \mathrm{abc}$ & $34275 \mathrm{ab}$ & $47,17 \mathrm{ab}$ \\
\hline AG4051 & $5089 \mathrm{c}$ & $29600 \mathrm{bcd}$ & $46,91 \mathrm{ab}$ \\
\hline XB7116 & 7409ab & $31553 \mathrm{bc}$ & $45,44 \mathrm{bc}$ \\
\hline Cativerde 2 & $5142 \mathrm{c}$ & $33521 \mathrm{abc}$ & $44,69 \mathrm{c}$ \\
\hline $20 \mathrm{~A} 55$ & $5215 \mathrm{c}$ & $27643 \mathrm{~cd}$ & $48,73 a$ \\
\hline BM3061 & $8276 a$ & $38290 \mathrm{a}$ & $46,26 a b$ \\
\hline 2B587 & $5909 \mathrm{bc}$ & $25212 d$ & $47,52 \mathrm{ab}$ \\
\hline \multicolumn{4}{|l|}{ Sistema de cultivo } \\
\hline Convencional & $6956 a$ & $36274 a$ & $47,54 a$ \\
\hline Orgânico & $5591 \mathrm{~b}$ & $26610 \mathrm{~b}$ & $45,54 \mathrm{~b}$ \\
\hline Média & 6273 & 314423 & 46,68 \\
\hline \multicolumn{4}{|l|}{ Teste F } \\
\hline Cultivar (C) & $6,56^{* *}$ & $9,84^{* *}$ & $7,19^{* *}$ \\
\hline Sistema (S) & $13,37^{* *}$ & $83,24^{* *}$ & $20,95^{* *}$ \\
\hline CXS & $1,24^{\mathrm{ns}}$ & $1,67^{\mathrm{ns}}$ & $0,21^{\mathrm{ns}}$ \\
\hline C.V. $\%$ & 22,27 & 12,60 & 3,04 \\
\hline Cultivar & & 2011 & \\
\hline AG1051 & $8617 \mathrm{a}$ & $39662 \mathrm{ab}$ & $49,13 a$ \\
\hline AG4051 & $6811 \mathrm{ab}$ & $35750 \mathrm{abc}$ & $48,30 \mathrm{ab}$ \\
\hline XB7116 & $7400 \mathrm{ab}$ & $34206 b c$ & $46,78 b c$ \\
\hline Cativerde 2 & $6187 \mathrm{~b}$ & $38906 \mathrm{ab}$ & $46,12 \mathrm{c}$ \\
\hline $20 \mathrm{~A} 55$ & $6119 b$ & $30962 \mathrm{c}$ & $48,05 \mathrm{abc}$ \\
\hline ВM3061 & 7795ab & $41750 \mathrm{a}$ & $47,21 \mathrm{abc}$ \\
\hline 2B587 & $6696 a b$ & $29280 \mathrm{c}$ & $48,46 \mathrm{ab}$ \\
\hline \multicolumn{4}{|l|}{ Sistema de cultivo } \\
\hline Convencional & $7689 a$ & $40201 \mathrm{a}$ & $48,37 \mathrm{a}$ \\
\hline Orgânico & $6490 \mathrm{~b}$ & $31374 b$ & $47,07 \mathrm{~b}$ \\
\hline Média & 7089 & 35788 & 47,72 \\
\hline \multicolumn{4}{|l|}{ Teste F } \\
\hline Cultivar (C) & $2,75^{*}$ & $8,95^{* *}$ & $5,15^{* *}$ \\
\hline Sistema (S) & $8,44^{* *}$ & $57,04^{* *}$ & $13,62^{* *}$ \\
\hline CXS & $1,31^{\mathrm{ns}}$ & $1,82^{\mathrm{ns}}$ & $1,07^{\mathrm{ns}}$ \\
\hline C.V. $\%$ & 21,77 & 12,22 & 2,76 \\
\hline
\end{tabular}


Para comprimento de espigas houve interação significativa entre cultivar e sistema de cultivo (Tabela 7). No sistema convencional destacaram-se principalmente as cultivares AG4051, BM3061 e AG1051, com espigas mais compridas e, no sistema orgânico, a cultivar BM3061. No primeiro ano, a cultivar AG4051 produziu espigas menores no sistema orgânico em comparação com o tamanho das espigas no sistema convencional. As demais cultivares apresentaram comprimento similar nos dois sistemas. No segundo ano, não houve efeito significativo dos sistemas de cultivo sobre o comprimento das espigas nas cultivares BM3061 e 2B587. Já a cultivar XB7116 produziu espigas menores no sistema convencional.

Tabela 7. Desdobramento das interações significativas entre sistema de cultivo e cultivar para comprimento de espigas de milho-verde cultivado em 2010 e 2011, Andradina-SP.

\begin{tabular}{|c|c|c|c|}
\hline \multirow{3}{*}{ Tratamentos } & \multicolumn{3}{|c|}{ Comprimento de espigas (cm) } \\
\hline & \multicolumn{3}{|c|}{2010} \\
\hline & Convencional & & Orgânico \\
\hline AG1051 & $18,63 \mathrm{Ab}$ & & $18,85 \mathrm{Abc}$ \\
\hline AG4051 & $19,36 \mathrm{Ab}$ & & $18,22 \mathrm{Bc}$ \\
\hline XB7116 & $19,02 \mathrm{Ab}$ & & $19,07 \mathrm{Aabc}$ \\
\hline Cativerde 2 & $18,79 \mathrm{Ab}$ & & $18,39 \mathrm{Ac}$ \\
\hline $20 \mathrm{~A} 55$ & $18,83 \mathrm{Ab}$ & & $19,58 \mathrm{Aabc}$ \\
\hline BM3061 & $20,58 \mathrm{Aa}$ & & $19,93 \mathrm{Aa}$ \\
\hline 2B587 & $18,36 \mathrm{Ab}$ & & $18,38 \mathrm{Ac}$ \\
\hline DMS C (S) & & 1,00 & \\
\hline DMS S (C) & & 0,65 & \\
\hline Média & & 19,00 & \\
\hline \multicolumn{4}{|l|}{ Teste F } \\
\hline Cultivar (C) & & $14,63^{* *}$ & \\
\hline Sistema (S) & & $1,79^{\mathrm{ns}}$ & \\
\hline CXS & & $3,67^{* *}$ & \\
\hline \multirow[t]{3}{*}{$\mathrm{CV} \%$} & & 2,40 & \\
\hline & \multicolumn{3}{|c|}{2011} \\
\hline & Convencional & & Orgânico \\
\hline AG1051 & $19,87 \mathrm{Aab}$ & & $18,65 \mathrm{Bab}$ \\
\hline AG4051 & $20,35 \mathrm{Aa}$ & & $18,92 \mathrm{Bab}$ \\
\hline XB7116 & $18,37 \mathrm{Bc}$ & & $19,36 \mathrm{Aa}$ \\
\hline Cativerde 2 & $19,10 \mathrm{Aabc}$ & & $18,01 \mathrm{Bbc}$ \\
\hline $20 \mathrm{~A} 55$ & $19,01 \mathrm{Abc}$ & & $18,20 \mathrm{Bac}$ \\
\hline BM3061 & $19,85 \mathrm{Aab}$ & & $19,44 \mathrm{Aa}$ \\
\hline 2B587 & $18,02 \mathrm{Ac}$ & & $17,26 \mathrm{Ac}$ \\
\hline DMS C (S) & & 1,32 & \\
\hline DMS S (C) & & 0,86 & \\
\hline Média & & 18,89 & \\
\hline \multicolumn{4}{|l|}{ Teste F } \\
\hline Cultivar (C) & & $11,16^{* *}$ & \\
\hline Sistema (S) & & $17,42^{* *}$ & \\
\hline CXS & & $3,57^{* *}$ & \\
\hline $\mathrm{CV} \%$ & & 3,19 & \\
\hline
\end{tabular}


Um ponto importante a ser observado na escolha da cultivar é que suas espigas permaneçam mais tempo em condições de comercialização. Albuquerque et al. (2008) verificaram que a cor dos grãos correlacionou negativamente com o tempo de comercialização das espigas embaladas em isopor com filme plástico. Neste sentido, exceto XB7116 e 20A55 com grãos alaranjados, todas as cultivares produziram espigas de cor clara, possivelmente apresentem maior tempo para serem comercializadas.

Demodogeral, destacaram-se pelocomportamento similar nos dois sistemas, as cultivares 2B587 e BM3061 com número total de espigas por hectare superior em 14 e $9 \%$, respectivamente. A cultivar 2B587 foi a mais precoce e com menor altura e BM3061 apresentou espigas com maior diâmetro e comprimento.

Os resultados de produtividade em cultivo orgânico foram semelhantes aos obtidos por Santos et al. (2005) porém utilizando doses maiores de adubação. Ao utilizar $30 \mathrm{t}$ de esterco, $440 \mathrm{~kg}$ de termofosfato, $111 \mathrm{~kg}$ de sulfato de potássio ha ${ }^{-1} \mathrm{e}$ biofertilizante, os autores obtiveram produtividade média de $7399 \mathrm{~kg}$ espigas despalhadas ha-1. Guedes et al. (2010) estudando a cultivar AG1051 sob cultivo orgânico no município de Seropédica- RJ, obtiveram produtividades menores, da ordem de $5960 \mathrm{~kg} \mathrm{ha}^{-1}$ de espigas despalhadas e 39375 espigas ha-1 utilizando $10 \mathrm{t}$ de esterco ha-1. Segundo Oliveira et al. (2011) as diferenças na performance de cultivares de milho são comuns em regiões tropicais e sistemas de produção com baixa ou alta entrada de insumos.

Produtividades menores no sistema orgânico em comparação com o sistema convencional a curto prazo foram relatadas por Pimentel et al. (2005). O menor aporte de nitrogênio no sistema orgânico provavelmente promove diferença de produtividade entre os sistemas, sendo que após os três primeiros anos, o nível de nutrientes melhora, deixando de ser um fator limitante para a produtividade. $\mathrm{O}$ menor desenvolvimento e produtividade observados nas plantas sob cultivo orgânico podem ser explicados pela adubação com composto que apresenta uma ação mais demorada em relação à adubação mineral. Embora a dose fornecida dos macronutrientes NPK fossem iguais para os dois sistemas de cultivo, estes não estavam prontamente disponíveis no momento da exigência da planta. Gomes et al. (2005) relatam que a dose de $40 \mathrm{t} \mathrm{ha}^{-1}$ de composto orgânico apresentou produção de milho semelhante à dose de $500 \mathrm{~kg} \mathrm{ha}^{-1}$ de adubo mineral NPK. Upnmoor (2003) ressalta que no sistema orgânico a nutrição vegetal é efetuada através do fornecimento de nutrientes carentes aos ecossistemas, com produtos de baixa solubilidade e baixa concentração e de lenta liberação. Os nutrientes são mineralizados e disponibilizados em doses contínuas para o aproveitamento das lavouras cultivadas em sucessão. Sugere-se portanto que, em áreas de conversão do plantio convencional para orgânico, doses de composto sejam mais elevadas (SILVA et al., 2004; GOMES et al., 2005; SANTOS et al., 2005) ou antecipadas.

Os dados deste trabalho demonstram a viabilidade da produção de espigas verdes em sistema orgânico. A escolha da cultivar em cada sistema de produção vai depender do nível tecnológico do produtor, do destino da produção e da disponibilidade de sementes.

\section{Conclusões}

No sistema orgânico as cultivares foram mais tardias, com menor desenvolvimento e produtividade.

Destacaram-se as cultivares 2B587 e BM 3061 com número total de espigas por hectare superior em 14 e 9\%, respectivamente. A cultivar 2B587 foi a mais precoce, com plantas mais baixas e BM3061 apresentou espigas com maior diâmetro e comprimento.

As cultivares AG4051 e Cativerde 02 apresentaram plantas mais altas e menos produtivas 
tanto no sistema convencional quanto no sistema orgânico.

As cultivares BM3061, 2B587, XB7116 e AG1051 podem ser recomendadas para os dois sistemas, por serem as mais produtivas em ordem decrescente.

\section{Agradecimentos}

À Fundação de Amparo a Pesquisa do Estado de São Paulo (FAPESP) pelo apoio financeiro.

\section{Referências}

ALBUQUERQUE, C. J. B.; VON PINHO, R. G.; BORGES, I. D.; SOUZA FILHO, A. X.; FIORINI, I. V. A. Desempenho de híbridos experimentais e comerciais de milho para produção de milho verde. Ciência $e$ Agrotecnologia, Lavras, v. 32, n. 2, p. 768-775, 2008.

ANUÁRIO DA AGRICULTURA BRASILEIRA AGRIANUAL. São Paulo: Instituto FNP, 2015. 472 p.

ARAÚJO, P. C.; PERIN, A.; MACHADO, A. T.; ALMEIDA, D. L. Avaliação de diferentes variedades de milho para o estádio de "verde" em sistemas orgânicos de produção. In: CONGRESSO NACIONAL DE MILHO E SORGO, 23., 2000, Uberlândia. Anais... Sete Lagoas: ABMS, 2000. 4 p. CD-ROM.

BORDALLO, P. N.; PEREIRA, M. G.; AMARAL JUNIOR, A. T.; GABRIEL, A. P. C. Análise dialélica de genótipos de milho doce e comum para caracteres agronômicos e proteína total. Horticultura Brasileira, Brasília, v. 23, n. 1, p. 123-127, 2005.

BOTTINI, P. R.; TSUNECHIRO, A.; COSTA, F. A. G. Viabilidade da produção de milho-verde na "safrinha". Informações Econômicas, São Paulo, v. 25, n. 3, p. 4953, 1995.

BRASIL. Ministério da Agricultura, Pecuária e Abastecimento. Instrução Normativa $n^{\circ} 64$, de 18 de dezembro de 2008. Diário Oficial [da] União, Poder Executivo, Brasília, 19 dez. 2008. Seção 1, p. 21.

CARDOSO, M. J.; CARVALHO, H. W. L; RIBEIRO, V. Q. Avaliação preliminar de cultivares de milho para produção de espiga verde em sistema agrícola familiar. Revista Ciência Agronômica, Fortaleza, v. 35, n. 2, p. 406-409, 2004.
CRUZ, J. C.; PACHECO, C. A. P.; PEREIRA FILHO, I. A.; OLIVEIRA, A. C.; QUEIROZ, MATRANGOLO, W. J. R.; MOREIRA, J. A. A. Variedades de milho em sistema orgânico de produção. Sete Lagoas: Embrapa Milho e Sorgo, 2008. 4 p. (Comunicado técnico, 158).

CRUZ, J. C.; PEREIRA FILHO, I. A. Cultivares de milho. In: CRUZ, J. C.; KARAM, D.; MONTEIRO, M. A.; MAGALHÃES, P. C. (Ed.). Cultura do milho. Sete Lagoas: Embrapa Milho e Sorgo, 2008. p. 159-170.

DUARTE, J. O.; PEREIRA FILHO, I. A.; CRUZ, J. C.; GOMES e GAMA, E. E.; TSUNECHIRO, A. Aspectos econômicos da produção e comercialização de milhoverde. In: CONGRESSO NACIONAL DE MILHO E SORGO, 25., 2004, Cuiabá. Anais... Sete Lagoas: ABMS, 2004. 10 p. CD-ROM.

EMPRESA BRASILEIRA DE PESQUISA AGROPECUÁRIA - EMBRAPA. Sistema Brasileiro de Classificação dos solos. Rio de Janeiro: Embrapa/SPI, 2006. $360 \mathrm{p}$.

FREIRE, F. M.; VIANA, M. C. M.; MASCARENHAS, H. T.; PEDROSA, M. W.; COELHO, A. M.; ANDRADE, C. L. T. Produtividade econômica e componentes de produção de espigas verdes em função da adubação nitrogenada. Revista Brasileira de Milho e Sorgo, Sete Lagoas, v. 9, n. 3, p. 213-222, 2010.

GOMES, J. A.; SCAPIM, C. A.; BRACCINI, A. L.; VIDIGAL FILHO, P. S.; SAGRILO, E.; MORA, F. Adubações orgânica e mineral, produtividade do milho e características físicas e químicas de um Argissolo Vermelho-Amarelo. Acta Scientiarum Agronomy, Maringá, v. 27, n. 3, p. 521-529, 2005.

GUEDES, R. E.; RUMJANEK, N. G.; XAVIER, G. R.; GUERRA, J. G. M.; RIBEIRO, R. L. D. Consórcios de caupi e milho em cultivo orgânico para produção de grãos espigas verdes. Horticultura Brasileira, Brasília, v. 28, n. 2, p. 174-177, 2010.

OLIVEIRA, L. R.; MIRANDA, G. V.; DeLIMA, R. O.; SOUZA, L. V.; GALVÃO, J. C. C.; SANTOS, I. C. Combining ability of tropical maize cultivars in organic and conventional production systems. Ciência Rural, Santa Maria, v. 41, n. 739-745, p. 739-745, 2011.

OLIVEIRA, T. K.; CARVALHO, G. J.; MORAES, R. N. S.; JERÔNIMO JÚNIOR, P. R. M. Características agronômicas e produção de fitomassa de milho-verde em monocultivo e consorciado com leguminosas. Ciência e Agrotecnologia, Lavras, v. 27, n. 1, p. 223227, 2003. 
PAIVA JUNIOR, M. C.; VON PINHO, R. G.; VON PINHO, E. V. R.; RESENDE, S. G. Desempenho de cultivares para a produção de milho-verde em diferentes épocas e densidades de semeadura em Lavras-MG. Ciência e Agrotecnologia, Lavras, v. 25, n. 5, p. 12351247, 2001.

PARENTONI, S. N.; GAMA, E. E. G.; MAGNAVACA, R.; REIFSCHNEIDER, F. J. B.; BOAS, G. L. V. Milho doce. Informe Agropecuário, Belo Horizonte, v. 14, n. 165, p. 17-22, 1990.

PEREIRA FILHO, I. A.; CRUZ, J. C.; GOMES e GAMA, E. E. Cultivares para consumo verde. In: PEREIRA FILHO, I. A. (Ed.). O cultivo do milho-verde. Brasília: Embrapa Informação Tecnológica, 2003. p. 17-30.

PINHO, L.; PAES, M. C. D.; ALMEIDA, A. C.; COSTA, C. A. Qualidade de milho-verde cultivado em sistemas de produção orgânico e convencional. Revista Brasileira de Milho e Sorgo, Sete Lagoas, v. 7, n. 3, p. 279-290, 2008.

PIMENTEL, D.; HEPPERLY, P.; HANSON, J.; DOUDS, D.; SEIDEL, R. Environmental, energetic and economic comparisons of organic and conventional farming systems. BioScience, Oxford, v. 55, n. 7, p. 573-582, 2005.

RAIJ, B. V.; CANTARELLA, H. Milho-verde e milho doce. In: RAIJ, B. van.; CANTARELLA, H.; QUAGGIO, J. A.; FURLANI, A. M. C. (Ed.). Recomendações de adubação e calagem para o Estado de São Paulo. Campinas: IAC, 1996. p. 64-65. (Boletim técnico, 100).
ROCHA, D. R.; FORNASIERI FILHO, D.; BARBOSA, J. C. Efeitos da densidade de plantas no rendimento comercial de espigas verdes de cultivares de milho. Horticultura Brasileira, Brasília, v. 29, n. 3, p. 392-397, 2011.

SANTOS, I. C.; MIRANDA, G. V.; MELO, A. V.; MATTOS, R. N.; OLIVEIRA, L. R.; LIMA, J. S.; GALVÃO, J. C. C. Comportamento de cultivares de milho produzidos organicamente e correlações entre características das espigas colhidas no estádio verde. Revista Brasileira de Milho e Sorgo, Sete Lagoas, v. 4, n. 1, p. 45-63, 2005.

SANTOS, N. C. B.; ARF, O.; KOMURO, L. Consórcio de feijoeiro e milho-verde na entressafra. II. Comportamento das cultivares de milho. Bioscience Journal, Uberlândia, v. 26, n. 6, p. 873-881, 2010.

SILVA, J.; SILVA, P. S. L.; OLIVEIRA, M.; SILVA, K. M. B. Efeito do esterco bovino sobre os rendimentos de espigas verdes e de grãos de milho. Horticultura Brasileira, Brasília, v. 22, n. 2, p. 326-331, 2004.

UPNMOOR, I. Agricultura orgânica: produção vegetal. Guaíba: Agropecuária, 2003. 62 p.

VIEIRA, M. A.; CAMARGO, M. K.; DAROS, E.; ZAGONEL, J. Z.; KOEHLER, H. S. Cultivares de milho e população de plantas que afetam a produtividade de espigas verdes. Acta Scientiarum Agronomy, Maringá, v. 32, n. 1, p. 81-86, 2010. 
